\title{
Presencia y función de los saberes psi en la "Edad de oro" de la literatura de Ciencia Ficción chilena (1959- 1973) ${ }^{1}$
}

\section{Presence and Function of Psi Knowledge in the "Golden Age" of Chilean Science Fiction (1959-1973)}

\author{
FRANCISCO PIZARRO OBAID \\ MARIANO RUPERTHUZ HONORATO \\ Universidad Diego Portales, Facultad de Psicología. Santiago, Chile. \\ Correo electrónico: francisco.pizarro@udp.cl \\ Universidad Andrés Bello, Escuela de Psicología. Santiago, Chile. \\ Correo electrónico: mariano.ruperthuz@unab.cl
}

\begin{abstract}
Las obras de Hugo Correa, María Elena Aldunate y Antonio Montero han sido reconocidas como aportes cruciales al desarrollo de la ciencia ficción chilena, dando lugar a la llamada "Edad de oro" del género (1959-1973). Si bien en sus novelas y relatos se aprecia una problematización de las transformaciones socioculturales de su época, es posible constatar, a su vez, que sus escritos incorporaron referencias conceptuales provenientes de la psicología, la psiquiatría y el psicoanálisis -saberes psi- en la configuración de la trama y los rasgos de sus personajes. El presente artículo buscará identificar la presencia de conceptos provenientes del campo de los saberes psi en la obra de los tres autores y analizará los posibles efectos literarios que tuvieron en la construcción de los argumentos y los personajes de sus relatos. De este modo, la singularidad de las obras del periodo no podría ser reducida a su sensibilidad social o al uso de categorías tecnológicas o científicas; además de interpretar los conflictos socioculturales, la ciencia ficción chilena de aquella década evidenció un marcado interés por los dilemas de la subjetividad, al abordar los problemas de lo mental, la inteligencia, la percepción, el yo psicologizado, la angustia y la alteridad, mediante la incorporación de saberes psi en el proceso de creación literaria.
\end{abstract}

Palabras claves: ciencia ficción chilena, Hugo Correa, Elena Aldunate, Antonio Montero, saberes psi.

\footnotetext{
${ }^{1}$ Artículo desarrollado en el marco del Proyecto FONDECYT regular № 1180629 (2018-2020): "Presencia y función de los saberes psi en la "Edad de oro" de la literatura de ciencia ficción chilena (1959- 1973)". Investigador Responsable: Francisco Pizarro Obaid.
} 
The works of Hugo Correa, María Elena Aldunate and Antonio Montero have been recognized as crucial contributions in the development of Chilean Science Fiction, giving rise to the so-called "Golden Age" of the genre (1959-1973). Despite that their novels and stories problematize the sociocultural transformations of their time, their writings also incorporated conceptual references from psychology, psychiatry and psychoanalysis - psi knowledge- in the configuration of the plot and the features of its characters. The present article seeks to identify the presence of concepts coming from the field of psi knowledge in the work of these three authors and analyze the literary effects they had in the construction of the arguments and the characters of their stories. In this way, the singularity of the works of this period could not be reduced to their social sensitivity or the use of technological or scientific categories. In addition to interpreting socio-cultural conflicts, Chilean Science Fiction of that decade showed a marked interest in the dilemmas of the subjectivity of its time by addressing the problems pertaining mental, intelligence, perception, psychological self, anxiety, and alterity through the incorporation of psi knowledge in the process of literary creation. knowledge.

Key words: Chilean science fiction, Hugo Correa, Elena Aldunate, Antonio Montero, Psi

\section{INTRODUCCIÓN}

Los estudios sobre literatura fantástica y ciencia ficción chilena han sido esporádicos y solo alcanzaron su consolidación hacia fines del siglo XX (Bell y Hasson 1998: 285; Areco 2009: 37; Novoa 2006: 15; Molina-Gavilán et al. 2007: 369; Haywood 2011: 10). Este logro no estuvo exento de complejidades, ya que los investigadores debieron sortear desafíos teóricos y metodológicos, así como también prejuicios que catalogaban a la ciencia ficción latinoamericana y por tanto a la chilena como un género menor (Fernández 1996: 592) o como la repetición de una fórmula extranjera o inauténtica (Ginway y Brown 2012: 1)2.

Desde un punto de vista literario, recientes investigaciones sobre la ciencia ficción latinoamericana han permitido reconstruir sus antecedentes, identificar a sus principales representantes (Bell y Molina-Gavilán 2003: 7), reconocer sus tópicos literarios y proponer hipótesis interpretativas, dando lugar a nuevas antologías y reediciones (Rojas-Murphy 1988: 7; Novoa 2006: 21; Heiremans et al. 2016: 11; Cortés y Jaque 2011: 7). Paulatinamente un género marginalizado e ignorado, fue reconocido ahora como una literatura relevante y como un valioso objeto de investigación de alcances históricos, sociales y antropológicos.

\footnotetext{
${ }^{2}$ Ginway y Brown (2012) precisan que la ciencia ficción fue rechazada en Latinoamérica "[...] por su falta de un obvio referente social o político contemporáneo, así como por su supuesta inferioridad frente al realismo mágico, el que ocupó un lugar central en la conexión entre la literatura fantástica y América Latina [...]. Por estas razones, la CF se consideró como extranjera o inauténtica” (1).
} 
Entre los resultados más significativos de aquel itinerario, Los Altísimos (1959) de Hugo Correa ${ }^{3}$ fue catalogada como una pieza crucial de la ciencia ficción nacional y latinoamericana (Remi-Maure et al. 1984: 181; Bell y Molina-Gavilán 2003: 140) por lo que algunos autores concluyeron que la novela habría inaugurado la "primera Edad de oro" (Bell y Molina Gavilán 2003: 7), una "década prodigiosa” (Hasson 2003: 37) o "el periodo de madurez" (Vega 2005: 8) de la ciencia ficción chilena ${ }^{4}$. En el transcurso de las investigaciones, dos autores además de Correa fueron considerados figuras emblemáticas de este periodo: María Elena Aldunate Bezanilla (1925- 2005), la "Dama chilena de la ciencia ficción”, y Antonio Montero Abt (1921-2013), quien bajo el pseudónimo de Antoine Montagne aportó varios cuentos y novelas al género (Bell 2013: 2017).

Si bien las obras de aquella etapa rindieron tributo a los máximos referentes del género (H. G. Wells, Ray Bradbury e Isaac Asimov) y a los tópicos más recurrentes de la ciencia ficción internacional (anticipación, extraterrestres, universo, viajes estelares, distopías), es posible constatar que no se trató, simplemente, de la reproducción del canon fantástico anglosajón. A través de aparatos tecnológicos, principios científicos y tramas sobrenaturales, los autores chilenos tematizaron críticamente las transformaciones socioculturales de su época y los procesos modernizadores registrados en Chile y Latinoamérica. De este modo, fueron receptores y agentes activos de la ciencia ficción, adaptando las formas más recurrentes del género a la realidad local y a las preocupaciones de su tiempo.

Pero la particularidad de las obras del periodo no se redujo a esta sensibilidad social; además de interpretar los conflictos socioculturales, la ciencia ficción chilena mostró un marcado interés por los dilemas de la subjetividad, perspectiva que se tradujo en un sistemático abordaje de lo mental, la inteligencia, la percepción, el yo psicologizado, la angustia, la culpa, el sentido freudiano de los actos, la sublimación de los impulsos, la identidad y el deseo, como elementos que enriquecieron sus relatos. Se podría afirmar, entonces, que en el proceso creativo Correa, Aldunate y Montero incorporaron un amplio repertorio de categorías psicológicas, psicopatológicas y psicoanalíticas -también llamados saberes $p s i^{5}$-,

\footnotetext{
${ }^{3}$ La obra de Hugo Correa (1926-2008) marcó un hito. Entre los primeros reconocimientos internacionales que obtuvo se cuentan - a sugerencia de Ray Bradbury - la publicación de sus relatos "El último elemento" y "Meccano" en las revistas norteamericanas The Magazine of Fantasy and Science Fiction (1962) -la publicación más destacada de ciencia ficción en lengua inglesa- e International Science Fiction (1968). En España, la revista Nueva Dimensión (1972) -la publicación más importante de habla hispana- consagró un número especial a su obra. Pero aún más llamativo resulta la inclusión del cuento "Alter Ego" de Hugo Correa en el libro Introductory psychology through science fiction (Katz et al. 1981: 427), un texto académico destinado a ilustrar conceptos de psicología general a través de cuentos de ciencia ficción; la inserción del relato de Correa en el apartado dedicado a la personalidad era útil, según los autores, para el estudio de la Teoría del Self y sus vínculos con la psicología existencial.

${ }^{4}$ El periodo se extendería, según los investigadores, entre 1959 y mediados de los setenta.

5 "Utilizamos la expresión "psi” como sinónimo de "psicológico" en su sentido más amplio. De modo que cuando hablamos de "disciplinas psi" o "discursos psi" lo hacemos en términos generales, aludiendo a todo discurso o disciplina que se ocupe de lo psíquico. Nada suponen estas expresiones respecto de las relaciones de inclusión y exclusión entre psicología, psicoanálisis y psiquiatría” (Dagfal 2009: 28).
} 
como recursos literarios que en el proceso creador alcanzaron un nuevo estatuto conceptual que sería perfectamente detectable y pesquisable a través de un proceso investigativo.

A partir de estos antecedentes, el presente artículo buscará ilustrar la presencia y las posibles funciones que tuvieron los saberes psi en la literatura de ciencia ficción chilena (1959- 1973), particularmente, en las obras de Hugo Correa, María Elena Aldunate y Antonio Montero, evidenciando el diálogo y el contacto que tuvieron la literatura de ciencia ficción y los saberes psicológicos en Chile.

\section{Correa, Aldunate y Montero: Perspectivas sobre la ciencia ficción}

$\mathrm{Al}$ analizar la aproximación que tuvieron Correa, Aldunate y Montero a la ciencia ficción, se podría decir que sus trabajos problematizaron, de una u otra manera, el estatuto y los límites de la ciencia, pero al mismo tiempo fueron críticos con la definición y las fronteras literarias del género. Por ejemplo, aunque Hugo Correa (1973a) expresó su admiración por Fiódor Dostoievski, Eugene O’ Neill, Franz Kafka, Thomas Mann, Hermann Hesse, Edgar Allan Poe, H.P. Lovecraft, Giovanni Papini, y reconoció a Ray Bradbury y H. G. Wells como su mayor influencia, fue crítico de la categoría de ciencia ficción. A su juicio, la ciencia ficción debía ser considerada como "la literatura del cambio, no de la ciencia", argumentando que "instintivamente se tiende a asimilar la ciencia-ficción al ensayo científico. Pienso que es un género propio de nuestra época" (Correa 1973a: 40); bajo esa perspectiva agregaba, más tarde, que el arte debía ser concebido como una "síntesis o decantación de muchas inquietudes de la época" (Correa 1975: 5), por lo que la misión del artista y del escritor era "ser un testigo de su época; por eso no puede falsear ni ocultar la realidad" (Correa 1994: 31).

En un diálogo con Antonio Montero, Correa sostuvo, incluso, que la ciencia ficción debería llamarse, en rigor, realismo-fantástico, argumentando que "el nombre salió de un mal traducido "science fiction" norteamericano, porque "fiction" es toda literatura imaginativa, como se dice, para separarla de la historia o del ensayo, o de cualquier género que alude a hechos rigurosos" (Correa y Montero 1977: 70). En este sentido, no es de extrañar que la editorial de la Revista Nueva Dimensión (1972), señalara: "Es difícil definir a Hugo Correa dentro de un estilo de narrativa. Su ciencia ficción, a caballo de la fantasía pura, es más humanística que técnica, mucha más ficción que ciencia, y en este aspecto entra de lleno en este lado de la ciencia ficción sudamericana, tan alejada de los patrones anglosajones (5).

Por su parte -y a diferencia de Correa- Elena Aldunate recurrió a lo fantástico y la ciencia ficción para analizar y reflexionar sobre lo femenino, lo materno y lo amoroso, en un contexto donde los debates de género comenzaban a difundirse en la sociedad chilena. Pese a ello, no se consideraba feminista, sino más bien, una mujer que reivindicaba las particularidades de lo femenino. Con un tono ambivalente expresaba, a fines de los noventa, su postura respecto del feminismo: "Como decía mi madre es un mal necesario, pero lo que tú tienes que tratar es ser femenina. Yo soy partidaria de la mujer, pero de esa mujer. A la otra, la feminista, la considero muy valiente" (Aldunate y Valdés 1993: 112- 113). 
En la misma perspectiva, al ser interrogada sobre la causa de su gran interés por el mundo femenino, sostenía, aludiendo a la dimensión psicológica del problema: "Creo que, así como el hombre encuentra que la mujer es difícil de entender, a mí con el hombre me ocurre eso. Siempre me meto dentro de la mente de mis personajes, en sus zonas más profundas y misteriosas. No sé cómo siente realmente un hombre" (Aldunate y Ibarra 1993: 6-7).

De esta manera, es distintivo en la escritura de Aldunate que los protagonistas de sus obras sean mujeres. Sin embargo, como advierte Schoennenbeck, estos personajes se revelan con la particularidad de ser "carentes de aquello que podemos identificar, gracias a la tradición del melodrama, con lo emocional, lo afectivo y el deseo erótico" (11). En este sentido, y desmarcándose de las representaciones clásicas de la mujer, su obra ilustra los cambios en la literatura y la sociedad chilena durante la segunda mitad del siglo XX: "refleja la lucha de la mujer por expresarse y romper con los estereotipos. Con las nuevas tendencias feministas y los trastornos políticos en el Chile de los setenta, la obra de Aldunate se orienta hacia la utopía fantástica o la ciencia ficción” (Loach 1999: 331-332). Pero, como puntualiza Guijarro-Crouch (2004), en sus trabajos son igualmente recurrentes "el miedo y la curiosidad activada por lo desconocido (...) la necesidad de comunicación entre sus personajes, los cuales rompen la barrera del tiempo, espacio y especies, para alcanzarlo" (13).

Un tercer referente del periodo fue Antonio Montero; ingeniero civil, sin estudios formales de literatura, que desarrolló una trayectoria donde es posible distinguir, según Coppola, tres momentos creativos: "[...] los así llamados relatos de ciencia-ficción; la cuentística y narrativa breve y su novelística" (5). Si bien su incursión en la ciencia ficción fue acotada, dio lugar a una trilogía emblemática: Los superhomos (1962), Acá del tiempo (1968) y sus relatos reunidos bajo el título No morir (1971). Marcadas por un sello cosmopolita, este conjunto de obras trató los principales tópicos del género, al incorporar entre sus ejes argumentativos la anticipación, los extraterrestres, los viajes espaciales, las guerras mundiales, la amenaza atómica, entre otros.

Dada las vicisitudes políticas, económicas y personales, Montero se alejó de la ciencia ficción para abordar temas más realistas y contingentes, como quedó de manifiesto en su obra El círculo dramático (1981) -premio Municipal de Santiago-, donde el cuento El tipo sabe aludía, claramente, a los excesos de la dictadura chilena ${ }^{6}$. Hacia el final de su vida regresó a la escritura fantástica a través de su última novela $E l$ Cáliz, Thule y los Dioses (2012), donde los mitos, la religión y el universo se funden en una intriga internacional.

Con énfasis y estilos distintos, las obras de Correa, Aldunate y Montero edificaron la así llamada "Edad de oro" de la literatura de ciencia ficción chilena, vinculándose de manera ineludible a las temáticas que este género había posicionado a nivel internacional,

\footnotetext{
${ }^{6}$ Montero recordaba que ese cuento le valió ser censurado entre 1982 y 1985: "Déjeme que le cuente. Yo ni siquiera sabía quién era el Mamo Contreras, y bueno, el cuento llegó a manos de los militares. A partir de ahí, un auto negro estuvo estacionado fuera de mi casa por tres meses. Me salvé gracias a que un coronel de ejército amigo mío, habló con Contreras y le dijo -Mira, Antonio Montero es un tipo de bien, tendrá ideas distintas, pero no anda tirando bombas ni nada-. Mi amigo me hizo llamarlo todas las tardes durante un buen tiempo, para asegurase que yo estuviera a salvo" (Aranda 2008).
} 
tales como la vida artificial, los robots, las relaciones con las máquinas, el espacio sideral, la vida proveniente de otros planetas y la superación de la muerte. Pero las referencias tecnológicas, los principios científicos y las alusiones a lo desconocido, permitieron, a su vez, que estos autores abordaran, críticamente, las transformaciones socioculturales de su época ${ }^{7}$ y los cambios registrados en Chile y Latinoamérica: las crisis políticas; las disputas bélicas; los conflictos del mundo rural; los dilemas de la vida urbana y el impacto de la industrialización, entre otros (Bell 2013: 302).

Como precisan Gabriel Salazar y Julio Pinto (1999), entre los años veinte y el golpe militar, el estado liberal democrático chileno experimentó un proceso de construcción y desestabilización; económicamente, se implementó un estatismo productivista y se promovió el desarrollo nacional, lo que condujo, más tarde, a una política nacional de industrialización, acompańada por discursos nacionalistas. Asimismo, como señala Bernardo Subercaseaux (2011):

En el periodo 1950-1970, aunque con rasgos de periferia con relación al mundo euro-norteamericano puede hablarse en Chile, tal vez por primera vez-tomando en cuenta la magnitud y cantidad de cultura consumida por vías no institucionales- de una sociedad de masas modernas. Son años en que se da un proceso de masificación de sentidos colectivos, fundamentalmente vía radios y revistas (154).

En este sentido, se podría afirmar que la ciencia ficción chilena fue sensible a los significativos cambios que experimentaba la sociedad local hacia comienzos de los años sesenta, pero, además de su crítica social, mostró un significativo interés por los enigmas de la subjetividad.

Como se verá en el siguiente apartado, para llevar a cabo tal empresa, estos autores recurrieron, explícita o implícitamente, a un variado repertorio teórico proveniente de los saberes psi, campo que reúne una mezcla heterogénea de conceptos y principios provenientes de la psicología, el psicoanálisis y la psiquiatría. De este modo, la creación literaria de ciencia ficción, daría cuenta, al igual que otras expresiones artísticas (cine, teatro, revistas, etc.) del grado de asimilación que tuvieron los saberes psi en la cultura popular de los años sesenta. Su

\footnotetext{
${ }^{7}$ Por solo nombrar algunos hitos internacionales de la década: revolución cubana (1959); Guerra de Vietnam (1959); misiles nucleares rusos en Cuba (1962); revolución cultural en China (1965); guerra de los 6 días entre árabes y judíos (1967); misión espacial Apolo XI, EE. UU. (1969); primeros hombres en la superficie lunar (1969); asesinato de Martin Luther King (1969), etc.

${ }^{8}$ En aquella época, el Índice de Precios al Consumidor (IPC) alcanzaba un 33,3\%; se instituyen los ministerios del Trabajo y Previsión Social, y de Salud Pública (1959). El gobierno promulga la ley de Reforma Agraria No 15.020 (1962). Surgen programas nacionales intensivos de planificación familiar: píldoras y dispositivos intrauterinos (1964); Nacionalización Pactada del Cobre (1969); Golpe militar (1973). En el ámbito cultural, se inician las transmisiones de TV abierta y se perfila la Nueva Ola (1960); se emprende la reforma educacional que establece cuatro niveles: parvulario, básico, media y superior (1965); Pablo Neruda obtiene el Premio Nobel de Literatura (1971), etc. (Subercaseaux 1993).
} 
amplia recepción no sería extraña, si se considera que haciendo uso de estos recursos teóricos se creaba un horizonte de potenciales sentidos para los sujetos, a partir de los cuales, podían definirse y comprenderse a sí mismos en términos cognitivos, emocionales y conductuales (Illouz 2007: 20).

\section{3. "Saberes Psi” y literatura de CienCia ficción: El PROCESo CREATIVo}

Los más destacados exponentes de la ciencia ficción mundial -Asimov et al. (1986: 8), Lovecraft (2010: 27); Ballard (2006) - ya habían advertido que la literatura no podía ser indiferente a la subjetividad de su época, ni tampoco a los saberes vinculados a lo psíquico; sostenían que la naturaleza de los objetos que intervienen en lo fantástico y la ciencia ficción, tales como el miedo, la angustia, el terror, la conducta, la mente, la memoria, etc., están íntimamente relacionados. Sin embargo, el factor psicológico sería fundamental, no solo por los posibles efectos que podrían provocar en el lector, sino que también, como una dimensión decisiva en la configuración de la trama y los personajes de una obra de ciencia ficción.

$\mathrm{Al}$ revisar las obras claves de Correa, Aldunate y Montero, resulta indudable que sus textos se inspiraron en variados principios del campo científico de su época. No obstante, además de las evidentes referencias a las ciencias básicas (matemáticas, física, química), las ciencias aplicadas (biología, astronomía, ingeniería, aeronáutica) o la tecnología (robótica, telecomunicaciones), las obras incluyeron, a su vez, saberes psi en el abordaje del problema de lo mental, lo afectivo y lo social. Así como históricamente el encuentro entre literatura fantástica y saberes psi estuvo facilitado por la incorporación del mesmerismo, la frenología, la hipnosis, la craneología o el estudio de los nervios - referencias que Edgar Alan Poe explotó de forma magistral (Pizarro Obaid 2011: 79; Pizarro Obaid 2016: 183)- la diseminación de los postulados freudianos y psiquiátricos en la década del cuarenta del siglo XX promovió una nueva estrategia para renovar la forma de retratar y explicar la psicología de los personajes en diversos géneros literarios (Druet 2013: 2). Chile no estuvo ajeno a este proceso, tal como lo revela el uso que hizo la novela chilena de conceptos psicoanalíticos (Ruperthuz y Veto 2016: 15) y como lo haría la literatura fantástica y de ciencia ficción desde fines de la década de los cincuenta.

La asimilación de conceptos y teorías provenientes de los saberes psi no fue un proceso lineal ni homogéneo en las obras de Correa, Aldunate y Montero; su implementación fue variable y estuvo destinada a la ampliación de las posibilidades dramáticas y la escenificación de los conflictos que sus personajes enfrentaban. En esta perspectiva, Correa (1973) sostuvo, por ejemplo, que el desafío para un autor no residía en la inclusión estricta de la teoría científica en sus argumentos, ya que la validez conceptual "dejaría de lado un elemento indispensable para toda la obra de arte: el libre juego de la intuición de los autores" (170). Así, cabría sostener, tal como advierte Beatriz Sarlo (2004) que "la literatura no piensa como la ciencia, sino como cree que la ciencia piensa" (36). 
La introducción de un aparataje conceptual multidisciplinario no fue, entonces, un mero artilugio estilístico, sino más bien un proceso de innovación teórica a través del cual la literatura reconstruyó los conceptos, los reformó, los reinventó y creó una subjetividad novedosa para estructurar sus tramas y personajes (Pizarro Obaid 2012: 183). De este modo, si bien se trata de una operación literaria, sus implicancias, tienen, al mismo tiempo, un alcance epistemológico (Pizarro Obaid 2011: 79). Como sostendrá Bachelard: "Es en el momento que un concepto cambia de sentido cuando tiene el máximo de sentido, es entonces, verdaderamente, un acontecimiento de la conceptualización” (56).

Con todo, el campo de la ciencia ficción chilena fue un terreno propicio para la articulación de literatura y saberes psi. Los ejemplos, explícitos e implícitos de la presencia y tratamiento de conceptos psicológicos, psiquiátricos y psicoanalíticos, entre las obras producidas en el periodo de oro de la ciencia ficción chilena, son diversos y permiten ilustrar, nítidamente, el anudamiento entre literatura y saberes psi.

\section{Presencia y función de los Saberes en Psi en las obras de Correa, Aldunate y MonTERo}

Aunque existe una variada tradición interpretativa destinada a explorar las potenciales relaciones entre la dimensión psíquica y literaria -psicobiografía (Schultz 2005; Elms 1997); interpretación psicoanalitica clásica (Freud 1900; Bonaparte 1933; Rank 1973); la psicocrítica (Mauron 1963); interpretación psicoanalitica estructural (Lacan 1966)-comprender la forma y la función que cumplen conceptos psicológicos, psicoanalíticos o psicopatológicos en un escrito no supone, necesariamente, recurrir a la biografía de un autor para encontrar en sus conflictos inconscientes la clave interpretativa de su legado; ni tampoco usar (Eco 1992: 38) el texto fantástico o de ciencia ficción para exponer conceptos psicopatológicos o hacer de las categorías psicológicas la llave maestra para la comprensión de un relato. En este sentido, como advierte Starobinski (2008) una obra es tributaria de registros heterogéneos y diversos (literario, social, histórico, psíquico, teórico) que reunidos en el acto creativo producen una concordia discors, por lo que su abordaje requiere vincular la obra con "su origen psíquico, sus efectos remotos, el medio que la rodea. En esas circunstancias, los indicios principales no vendrán del afuera, será en las obras mismas en sus repliegues donde se los encontrará, a condición de saber descubrirlos y leerlos" (34).

A partir de estas consideraciones, es posible ilustrar la presencia y potenciales funciones de los saberes psi en algunos de los relatos de Correa, Aldunate y Montero, dando cuenta de la notable articulación entre ciencias básicas, ciencia aplicada, ficción y saberes psi.

El encuentro entre saberes psi y ciencia ficción tuvo en Los titeres (1969) de Hugo Correa un tratamiento literario ejemplar. En sus cuatro cuentos - "Alter Ego"; "El mundo del tío Roberto"; "El veraneante"; "El hombre prohibido"- se relata el conflictivo y fallido vínculo que establecen hombres y mujeres con los títeres, autómatas que son controlados por sus dueños humanos por medio de un dispositivo llamado casco introyectador. 
Fue el propio Correa quien develó la fuente conceptual que inspiró el diseñó del casco introyectador, una suerte de escafandra a través de la cual el humano puede interactuar y comunicarse con el mundo a través del títere. En la primera aparición de "Alter Ego" el editor de The Magazine of Fantasy \& Science Fiction señalaba: "Hugo Correa (...) escribe desde su Chile natal que esta historia está basada en el principio psicológico de la introyección" (1967: 77); más tarde, recalcando la originalidad de su propuesta, Correa precisaba que "en Estados Unidos siempre lo que se hacía eran dobles completos; no era la idea esa de "introyectarse" como digo yo ahí, buscando una expresión que hay en psicología, introyectarse dentro de un autómata, comenzar a vivir a través del autómata” (Barrientos y Correa 2002).

En una primera lectura el casco introyectador parecería ser un mero instrumento tecnológico que habilita la recepción y emisión de estímulos sensoriales; no obstante, un análisis crítico permite constatar que los mecanismos de comunicación entre el titere y su dueño refieren, en otro registro conceptual, a la introyección, un complejo mecanismo psíquico definido por el psicoanálisis para explicar la constitución del yo y comprender fenómenos psicopatológicos (Pizarro Obaid 2018: 32). Como advertía Ferenczi en 1912, la introyección puede ser definida como un mecanismo psíquico que promueve "[...] la extensión del interés de origen autoerótico al mundo exterior, mediante la introducción de los objetos exteriores en la esfera del yo" (2000b: 196). Bajo esta perspectiva, cabría reformular las posibles relaciones amorosas entre el yo y sus objetos, ya que, a partir de la intervención del dinamismo psíquico inconsciente, podría sostenerse que "en último término, el hombre solo se ama a sí mismo: amar a otro equivale a integrar al otro en su propio yo" (196).

Pero en el campo clínico la introyección no sirvió únicamente para comprender fenómenos de orden psicopatológico o aquellos relativos al Yo, como advirtió Ferenczi, sino que también favoreció el análisis de tempranos procesos de estructuración del aparato mental. En sus estudios acerca del desarrollo psíquico infantil, Melanie Klein dio un nuevo giro al concepto al postular que en los procesos de formación psíquica del bebé intervendría el mecanismo de la identificación proyectiva, una forma particular de identificación que establece "el prototipo de una agresiva relación de objeto" (Klein 1998: 17). Se trataría de una agresión por parte del bebé al objeto de amor (madre) a través de la inserción fantaseada de partes del propio yo (bebé) en la madre con el fin de controlarla y apoderarse de sus contenidos. Como sintetiza Hinshelwood (2004),

"es una fantasía alejada de la consciencia que supone una creencia en que ciertos aspectos del self están localizados en otra parte, con el consiguiente vaciamiento y debilitamiento del sentimiento de sí y la identidad, que tiene el alcance de una despersonalización: pueden venir profundos sentimientos de extravío o una sensación de aprisionamiento" (231).

En el relato "Alter Ego", primer cuento de Los títeres, el casco introyectador no solo habilita acciones físicas o sensoriales a través del doble, sino que es la personalidad del protagonista (Demetrio) la que se pone en juego a través de la máquina -"en cuanto Alter 
Ego abrió la boca, Demetrio se escuchó a sí mismo hablándose desde el medio del cuarto. -¿Cómo estás Demetrio? Has nacido de nuevo" (Correa 1969: 14).

El alter ego (títere), un avance tecnológico destinado a renovar el contacto con el mundo y los otros, un dispositivo que genera una ilusión de juventud que cumple la condición de un objeto narcisista que permitiría al Yo expandir su grandeza y el control sobre el mundo, exacerbando la función del mecanismo de la introyección. Pero, en este afán, la estabilidad psicológica del dueńo se altera, ya que el autómata se mimetiza hasta el punto de fundirse con el Yo del propietario, dando lugar a lo que en el campo psicopatológico se conoce como despersonalización y desrealización $n^{9}$. El efecto ominoso que produce el relato reside, fundamentalmente, en la conexión psicológica que se establece entre el dueño y su títere, en la verdadera simbiosis que precipita la conexión entre el autómata y la subjetividad del dueño. El títere devela su historia personal; juzga sus elecciones biográficas más cruciales y exacerba su culpa, recordándole que traicionó sus ideales de juventud a cambio de prestigio y ascenso social; con tono sarcástico devalúa sus logros y sus triunfos; se hace eco de su deseo y lo conduce a un desenlace fatal. Es tanto el personaje principal (Demetrio) quien vive un extrańamiento respecto de sí mismo, así como el lector quien, ante un giro insospechado, ve como el títere y el humano se confunden en la dinámica de la introyección/proyección, precipitada por un dispositivo tecnológico. Pero no se trata de una fusión material, ni una experiencia puramente sensoperceptiva; se trata del borramiento de los límites entre lo interno y lo externo, entre lo humano y lo maquinal, entre el pasado y el presente, entre lo consciente y lo inconsciente. El títere, mediante su interpelación (interpretación) no hace sino devenir consciente un deseo que Demetrio ha reprimido, develando su impostura y conminándolo a tomar, por fin, una decisión auténtica: ¿Quién es el títere? ¿Quién es el amo? ¿Quién ha triunfado? ¿Quién ha fracasado? De este modo, por medio de un recurso tecnológico - casco introyectador- Correa reformula el problema del autómata y reversiona, de manera novedosa, el clásico motivo del doble -celos, rivalidad, narcisismo, muerte- bajo los códigos de la ciencia ficción (Pizarro Obaid 2018: 31).

Pero no solo la obra Los titeres será ilustrativa de la presencia de saberes psi. El cuento "Cuando Pilatos se opuso", relato que da nombre a la compilación de cuentos publicada el ańo 1971, expone el drama que vivieron los tripulantes del Tierra al ser sometidos por los habitantes de un extraño planeta que habían recientemente conquistado. Inicialmente los dumis -seres monstruosos, mezcla de reptil e insecto y de hábitos caníbales- habían depuesto las armas y se mostraban serviles; sin embargo, secretamente, habían urdido una trampa para doblegar y someter a los hombres. Recreando la historia de Cristo, un dumi es

\footnotetext{
9 Para la Asociación Americana de psiquiatría (APA) estos fenómenos pueden definirse como: "1. Despersonalización: experiencias de irrealidad, distanciamiento, o de ser un observador externo respecto a los pensamientos, los sentimientos, las sensaciones, el cuerpo o las acciones de uno mismo (p. ej., alteraciones de la percepción, sentido distorsionado del tiempo, irrealidad o ausencia del yo y embotamiento emocional y/o físico). 2. Desrealización: experiencias de irrealidad o distanciamiento respecto al entorno (p. ej., las personas o los objetos se experimentan como irreales, como en un sueño, nebulosos, sin vida o visualmente distorsionados)" (302).
} 
llevado a la nave terrícola por orden del capitán Ortuzar (Pilatos), tras los rumores que lo signaban como un profeta que comenzaba a liderar a la masa y que sería sacrificado por el pueblo dumi. Ortuzar se opone al sacrificio, pero el dumi (profeta) infiltrado en el cohete intenta asesinarlo. $\mathrm{Al}$ repeler el ataque, el cuerpo despedazado del dumi libera un gas y toda la tripulación queda inconsciente a merced de los dumis, quienes toman, definitivamente, el control. El líder de los dumi concluye:

Si bien desconocemos los secretos científicos y técnicos de los humanos, somos grandes sicólogos. ¿Qué mejor que hacerles creer a los hombres que el Hijo de Dios había llegado a predicar sus doctrinas entre nosotros? El hombre no perdería la oportunidad de burlarse de Dios: en su retorcida mente nacería la ocurrencia de oponerse al sacrificio del Redentor: ¡Una demostración que el Hacedor había sido superado! Porque aquel que usted mató, capitán, no era un profeta ni el Hijo de Dios, era solo un dumi corriente" (1971: 98).

Apelando al conocimiento de la mentalidad terrícola, los dummies burlan el narcisismo de los hombres y sus ínfulas de superioridad y dominio; pero lo más relevante de todo es que su estrategia considera como pieza clave la manipulación del sentimiento de culpa que hipotetizan en la consciencia del líder humano. Suponen que los hombres intentarán evitar, de algún modo, el potencial remordimiento de consciencia derivado de la muerte del profeta; a partir de ello, urden la trampa; como estaba previsto, la inocencia y la culpa se funden de manera trágica.

La dinámica de sumisión y esclavitud tiene un elemento nominal que imprime un carácter paradójico al desenlace de la historia entre los hombres y los dumis; cabría conjeturar que la elección del nombre dumi no es azarosa y tiene relación con el término inglés dummy (en plural dummies): muñeco, títere, maniquí; como adjetivo refiere a estúpido, ficticio, simulado y, en sentido figurado, sustituto. Los dumis [dummies] esclavos, tontos y primitivos -a juicio de los hombres- conocen, sin embargo, la subjetividad humana y, en ese universo, un sentimiento cardinal - la culpa- que impregna no solo la tradición cristiana, sino que el orden cultural; en este sentido, la manipulación del narcisismo y el sentimiento de culpa, se transforman en las claves, para derrotarlos y someterlos.

Bajo otras coordenadas y apelando, tanto a lo fantástico como a los tópicos de la ciencia ficción, María Elena Aldunate ofreció en su cuento "El niño" -relato incluido en la obra Angélica y el delfin - una verdadera sesión psicoanalítica, en la que el Dr. Jonnson, un médico, busca comprender la extraña conducta del hijo de la Sra. Gutiérrez: "Cálmese, por favor, señora, tiene que decírmelo todo, es muy importante para que yo pueda entender y tratar el caso de su hijo. Los niños a veces tienen extrańas reacciones si ven que su madre sufre; ahora presiento que hay algo muy especial que Ud. aún no me ha revelado" (121).

Como queda de manifiesto en el cuento, considerar que los sujetos son afectados por fuerzas desconocidas que desafían la razón, no fue una hipótesis que rigió, exclusivamente, el dominio de los saberes psi, sino que se expandió a la cultura de masas y a diversos campos 
como la medicina y la criminología, entregando nuevas posibilidades y alternativas para comprender las causas de la conducta humana (Ruperthuz 2016: 225). Es interesante destacar, tal como ha sido analizado en otras investigaciones, la manera en que es representado el médico en la ficción (Ruperthuz y Veto 2016: 15). En este sentido, la escena del relato presenta a un médico, personificado como un psiquiatra, al cual, a partir de una filiación freudiana, se le atribuye una especial sensibilidad para intuir aspectos ocultos en el relato de sus pacientes. El acto médico evoca una escena psicoanalítica que sirve como marco de íntimas revelaciones; el gabinete médico es el lugar preciso para la expresión de fenómenos ocultos y el espacio para liberar a los sujetos que los padecen. El médico-psicoanalista es, entonces, un especialista que "entra" en la mente de sus pacientes para "sacar" lo oculto y más íntimo de ellos. Se podría decir, parafraseando a Eva Illouz (2007), que la imagen refleja el éxito sin igual del saber psicológico para sustentar las imágenes de un yo interior, altamente emocional y desconocido, que el sujeto se debe esforzar por conocer (15).

En concordancia con el relato anterior, en el cuento "La bella durmiente", contenido en la obra Angélica y el delfin (1976), Aldunate muestra una escena altamente tecnológica donde una mujer de una civilización ya extinta es sometida a variados procedimientos para develar los misterios de su historia. Los científicos a cargo del estudio implementan distintas estrategias de intervención y, después de la comunicación telepática, el psicoanálisis, en una suerte de 'transcripción fantástica', es considerado un método privilegiado de conocimiento: "se sometió a las ondas psicoanalíticas y en la pantalla profunda fueron desfilando las épocas de su infancia, con sus complejas reacciones primarias, los momentos de cambio y rebeldía de la pubertad, luego la lucha de superación personal" (68). La alusión a la teoría freudiana (desarrollo psicosexual, asociación libre, transferencia, recuerdo, trauma, interpretación), al igual que en el relato anterior es evidente y demuestra una concepción de psiquismo y una forma de comprender la alteridad de los personajes, en la que el concepto de inconsciente tiene una función central; su inclusión desafía los cánones de la razón y hace de la causa un enigma que interpela las clásicas nociones de tiempo y espacio. La escena freudiana tradicional es reformulada gracias a sofisticados dispositivos tecnológicos (las ondas psicoanalíticas que se plasman en una pantalla), redefiniendo el lento ejercicio de la sesión psicoanalítica ortodoxa. Asimismo, los resultados que en el proceso clínico habitual se obtienen paulatina y laboriosamente, en estos relatos son presentados de forma instantáne $\mathrm{a}^{10}$ a partir de su actualización tecnológica.

De la misma manera, otros conceptos y principios psicopatológicos formaron parte de los recursos que Aldunate incorporó en sus obras para problematizar las relaciones entre lo normal y lo patológico, la percepción y la alucinación. Así lo demuestra, por ejemplo, el cuento "Juana y la cibernética" de la compilación $E l$ señor de las mariposas, donde la mujer protagonista -Juana, una solitaria operaria de una fábrica de cuarenta y cuatro años- desafía

${ }^{10}$ La instantaneidad del dispositivo psi es una característica que otros autores chilenos como Juan Marín ya habían explorado en el campo literario. En su novela "Las aventuras del Dr. Baloux" presenta la historia de un médico que había inventado un gas que al aplicarse a los sujetos disolvía cualquier tipo de censura, expresando sus deseos inconscientes abiertamente (Ruperthuz y Veto 2016: 21). 
el hastío de la existencia y los límites de la realidad, por una vía alucinatoria. El relato expone las tediosas condiciones laborales de Juana y cómo el ahogo y la angustia desencadenan un episodio disociativo, donde sus nervios se ven inundados de sensaciones intempestivas que mezclan el placer, el dolor y la violencia. El componente sexual de las escenas es claro:

Un deseo tiránico se apodera de ella. Quiere sentir; no importa qué, pero sentir violentamente..., violentamente. Ambivalencia de dolor y placer, miedo y entrega. Su respiración comienza a seguir el jadeo de la máquina y vive, vive... Aferrada a ese ser tibio, duro, firme, viscoso, dominante, quiere más. Derecha, izquierda, arriba, abajo. Hasta la locura, hasta el dolor (...). Chispazos, ondas que ondulan la envuelven; ondas que salen de su ser, ondas, desconocidas, voluptuosas; extrańas prolongaciones que parecieran salir de un ser ajeno. Apetitos insospechados, fiebre, risa, cavidades blandas que ceden, rígidos metales que hieren. Lentamente, el dolor traspasa redes de nervios que estallan rasgando zonas olvidadas. El calor, la fricción, la fuerza, queman con rudo contacto mecánico, encendiendo, iluminando esa que fuera una vida gris (...) Desnudando el rechazo, la castidad, desde el fondo desquiciado de su experiencia célibe, la mujer entiende que ese ser la desea, la necesita, y que su expresión es quemante, lacerante (Aldunate 1967: 91-93).

La singular conjunción expresada ya en el nombre del relato "Juana y la cibernética" es significativa. La cibernética, teoría propuesta por Norbert Wiener (1988: 21) a mediados del siglo $X X$, no solo fue una disciplina que reunió principios relativos al control, la información y la comunicación en máquinas y sistemas tecnológicos, sino que fue, también, uno de los fundamentos que, junto a la Teoría General de Sistemas de Ludwing Von Bertalanffy (1976: 9), promovió la emergencia de un vasto campo de saberes psicológicos destinados a la comprensión de fenómenos individuales y grupales (terapia de parejas y familias; intervenciones en procesos y cultura organizacional, etc.). Conceptos claves del universo de la cibernética -entropía, feedback, relación, interrelación- están expuestos alegóricamente en el relato, pero son radicalizados por Aldunate para dar cuenta de una vida femenina que, en el encuentro mortal de la carne y el metal, ha descubierto un goce desconocido, una sensualidad hasta entonces vetada y un orgasmo definitivo. De este modo, el término cibernética, si bien alude al imaginario social de la maquinización, la industrialización, la modernización y los costos del progreso en la civilización, permite a su vez, tematizar la subjetividad humana al denunciar las penurias de la vida amorosa, el deseo y el erotismo de una humilde operaria de fábrica, que en un episodio de locura encuentra, finalmente, la liberación y el goce absoluto con la máquina.

Bajo una perspectiva distinta, y con un tono cosmopolita, Antonio Montero también recurrió a la psicología y el psicoanálisis para construir sus personajes y diseñar escenarios post atómicos y viajes estelares. En su novela Los superhomos relataba los esfuerzos de Verdiaschkin-avezado conocedor del cerebro y el comportamiento humano- por descifrar las sorprendentes y enigmáticas capacidades físicas y mentales de Rischevski: 
El fundamento de las tres zonas mentales es inevitable, y yo quiero encontrar el entrelazamiento que entre ellas debe existir ¿'Tiene realmente recuerdos de su "otra existencia"? Puedo hablarle así porque será imposible que ocultemos algo. "Yo", "Superyó", "Ello". Lo consciente, lo inconsciente y lo vital, instintivo o animal, si prefiere (1962: 66).

La referencia de Montero al modelo de aparato mental freudiano es directa (segunda tópica freudiana) y, como quedó de manifiesto en otras obras tales como Acá del tiempo o No morir, variados tópicos psicológicos -inteligencia, percepción, sensación, memoria y pensamiento- fueron incorporados para tensionar los límites de lo humano, dando lugar a una teoría de la subjetividad. En estos términos la mente es presentada al modo freudiano: fragmentada y con la necesidad de ser descubierta. Verdiaschkin es un investigador de la mente, combinando estos saberes con los de la física avanzada. Los escenarios catastróficos que relata este libro se combinan con la presencia de seres provistos de capacidades mentales superiores cuyo estudio requiere de herramientas conceptuales sofisticadas, entre las cuales, la teoría psicoanalítica resulta una poderosa fuente de conocimientos.

En su obra Acá del tiempo (1968) Montero nuevamente confronta al lector con un escenario post atómico fechado en el año 2158 donde un grupo de científicos de diversas nacionalidades (Joa Oliveira de Brasilia; Fernando Manizares de Cochabamba Bolivia; Pierre Guerrillat y Djorin Bergenstrom de Paris, entre otros), son reunidos por el eminente profesor Adolphe Challonier y conducidos a una misión decisiva: derrocar a la Administración Integral, régimen que gobierna el mundo tras la reorganización geopolítica derivada de las guerras y desastres atómicos. Después de hallar unas misteriosas cavernas cercanas a Ucayali, en el Amazonas, el científico descubre restos de una civilización hiper avanzada (a la que llamarán Cibernos), en la que habita una entidad maquinal (Máquina de la memoria infalible) de inteligencia y poderes mentales excepcionales con la cual entran en comunicación sensorial y telepática. Decidido a vincularse con el ente de conocimientos asombrosos-que además está dispuesto a sellar un pacto de colaboración con los humanos y otorgarles toda la información necesaria para derrocar al régimen-Challonier emprende sucesivas expediciones con el grupo científico. Todo el plan se desbarata y las confianzas del grupo se quiebran al develarse que el eminente Doctor Challonier sufre un grave trastorno mental agudizado por el poder manipulatorio del ente maquinal quien ha influido telepáticamente en él y en algunos colaboradores; en otras palabras, se trata de una rebelión animada por un componente delirante. La prueba ofrecida por las autoridades de la administración, las cuales han estudiado desde la niñez a los personajes que ocupan cargos en el nuevo orden, es su ficha psiquiátrica:

Paranoia acentuada; Autodefensa: proyección de amor hacia los demás. La psicohipnosis prueba que está consciente de su desviación mental y logra controlar su manía agresiva. Mente brillante, creadora. Megalomanía, intensos deseos de poder. Autodefensa: entrega hacia los demás en amistad completa. Sentimiento de culpa. Autodefensa: humildad... (1962: 218). 
Las referencias freudianas son claras, aludiendo al mecanismo de la proyección y a mecanismos de defensa inconscientes que permiten al sujeto mantener, aunque de manera frágil y costosa, la integridad de su personalidad. Asimismo, aparecen los peculiares métodos para explorar la mente; no se trata meramente de la hipnosis o la sugestión, sino de un procedimiento científico de estudio de lo mental: la psicohipnosis.

Con todo, y pese a las diferentes versiones que Correa, Aldunate y Montero tuvieron de la ciencia ficción, es posible afirmar que a partir de la intervención y reformulación de saberes psi la ciencia ficción chilena expuso en sus obras su propia versión de la mente, la vida afectiva y las formas de lazo social que regían los intercambios humanos contingentes y posibles. Se trataría, entonces, de un acto creativo y estético en el que la literatura, al tensionar los vínculos entre la ficción y la realidad, la razón y lo sobre natural, renovaría las categorías psicológicas y psicopatológicas (Pizarro Obaid 2011: 79).

\section{Conclusiones}

Las obras de referencia de la literatura de ciencia ficción chilena, correspondientes a la así llamada "Edad de oro" (1959-1973), problematizaron dimensiones sociales, políticas, culturales y económicas propias al proceso de modernización nacional, así como también, procesos relativos al ordenamiento geopolítico mundial. No obstante, los relatos y novelas del periodo incluyen, a su vez, categorías psicológicas, psicopatológicas y psicoanalíticas en la construcción de tramas y personajes, lo que evidencia la íntima relación que existe entre la literatura fantástica y de ciencia ficción con los saberes psicológicos. Estos vínculos, como se vio, enriquecieron las tramas entregando nuevos elementos a las problemáticas subjetivas de los personajes, tanto en sus explicaciones sobre el funcionamiento de la mente, así como en la representación de sus estados alterados.

La posibilidad de exploración mental se repite como una temática importante, recurriendo a metáforas freudianas y a distintas tecnologías que aceleraban el proceso clásico de autoconocimiento. Miedos, angustias y delirios son explicados a partir de categorías psicopatológicas y la mente aparece disociada en su vinculación con la modernidad; las máquinas, a su vez, son combinadas con inteligencias superiores en escenarios apocalípticos.

Todo lo anterior confirma que, si bien las principales figuras del periodo (19591973) -Hugo Correa, Antonio Montero y Elena Aldunate- desplegaron argumentos, temas y estructuras tradicionales al género fantástico y la ciencia ficción, sus obras interpretaron, al mismo tiempo, procesos de subjetivación (yo, identidad, alteridad) al crear imaginarios psicológicos en la producción de la ciencia ficción nacional de la época. 


\section{OBRAS CITADAS}

Aldunate, Elena. 1967. El señor de las mariposas. Santiago de Chile: Zig-Zag. . 1976. Angélica y el delfín. Santiago: Ediciones Aconcagua.

Aldunate, Elena y M. Loreto Valdés. 1993. "La mujer tiene más magia que el hombre". Revista Cosas 445: 112-113.

Aldunate, Elena y Carmen Luz Ibarra. 1993. "Hadas y extraterrestres". La Tercera (suplemento noviembre): 6-7.

American Psychiatric Association (APA). 2014. Manual diagnóstico y estadístico de los trastornos mentales: DSM-5. Madrid: Editorial Médica Panamericana.

Aranda, Juan. "Entrevista a Antonio Montero". 22, enero, 2008. Web. 1 de junio de 2018. http://www.puerto-de-escape.cl/2008/especial-de-antonio-montero/>.

Areco, Macarena. 2009. "Visión del porvenir, espejo del presente: Panorama de la ciencia ficción chilena”. Hispamérica 38.112: 37-48.

Asimov, Isaac, Charles Gordon Waugh y Martin Harry Greenberg. 1986. Orbita de alucinación: La psicología en la ciencia ficción. Ciudad de México: Roca.

Bachelard, Gaston. 1934. Le nouvel esprit scientifique. París: P. U. F.

Ballard, James. 2006. "Préface à l'édition française". Crash! Paris: Denoël.

Barrientos, Óscar y Hugo Correa. 2002. "Entrevista al escritor chileno de Ciencia Ficción Hugo Correa”. Internet Archive. https://archive.org/details/EntrevistaHugoCorrea.

Bell, Andrea y Moisés Hasson. 1998. "Prelude to the Golden Age: Chilean Science Fiction, 1900-1959”. Science Fiction Studies 25.2: 285-299.

Bell, Andrea y Yolanda Molina-Gavilán. 2003. Cosmos latinos: An Anthology of Science Fiction from Latin America and Spain. Middletown: Wesleyan University Press.

Bell, Andrea. 2013. "The critique of Chilean industrialization in Hugo Correa's avatar stories". Science-fiction Studies 40.2: 301-315.

. "Chile". The Encyclopedia of Science Fiction. Eds. John Clute, David Langford, Peter Nicholls and Graham Sleight. Gollancz, 22 abril 2015. Web. 23 de mayo de 2017. <http://www.sf-encyclopedia.com/entry/chile>.

Bertalanffy, Ludwig von. 1976. Teoría general de los sistemas. Ciudad de México: Fondo de Cultura Económica.

Bonaparte, Marie. 1933. Edgar Poe, étude psychanalytique. París : Denoël.

Coppola, Salvattori. 1994. Claves y aproximaciones: la narrativa obra de Antonio Montero $A B T$. Santiago de Chile: Ediciones Ateneo.

Correa, Hugo. 1959. Los Altísimos. Santiago de Chile: Editorial del Pacífico. . 1962. "The last element". En Avram Davidson, ed., The Magazine of Fantasy and Science Fiction April issue. New York: Mercury Press. 21-29.

. 1967. "Alter ego". En Edward L. Ferman, ed., The Magazine of Fantasy and Science Fiction. July issue. New York: Mercury Press. 77-79.

. 1968. "Meccano". En Frederik Pohl, ed., International Science-Fiction. June issue. New York: Galaxy Publishing Corporation. 104-107. 
1969. Los Titeres. Santiago de Chile: Zig-zag.

.1971. Cuando Pilato se opuso: Cuentos. Santiago de Chile: Ediciones Valores Literarios.

. 1973a. "A la búsqueda del demonio". Revista Ercilla 7/03: 39-40.

. 1973b. "Ciencia-ficción y futuro". En Luis Capurro, ed. El Impacto del futuro.

Valparaíso: Ediciones Universitarias de Valparaíso. 169- 206.

. 1975. "A veces es bueno hablar del demonio". La Tercera 26/5: 5.

. 1994. "El escritor es un testigo de su época". Las Últimas Noticias 5/02: 31.

Correa, Hugo y Montero, Antonio. 1977. "Hugo Correa y Antonio Montero. Profetas chilenos del apocalipsis". Revista Bravo 70.

Cortés, Macarena y Javiera Jaque. 2011. Cuentos de Elena Aldunate: La dama de la ciencia ficción. Santiago de Chile: Cuarto Propio.

Dagfal, Alejandro. 2009. Entre París y Buenos Aires: La invención del psicólogo, 1942-1966. Buenos Aires: Paidós.

Druet, Anne- Cecile. 2013. "La introducción del psicoanálisis en la literatura española a través de su representación". Asclepio 65.2: 1-11.

Eco, Umberto. 1992. Los límites de la interpretación. Barcelona: Lumen.

Elms, Alan. 1997. Uncovering Lives: The Uneasy Alliance of Biography and Psychology. New York: Oxford University Press.

Fernández, Maximinio. 1996. Historia de la literatura chilena: Tomo 1 y 2. Santiago de Chile: Salesiana.

Ferenczi, Sandor. 2000a. "Transfert et introjection (1909)". Oeuvres complètes I. Trad.

Judith Dupont. Paris: Payot. 93-125. . 2000b. "Le concept d'introjection (1912)". Oeuvres complètes: Tome I. Trad. Judith Dupont. Paris: Payot. 196-198.

Freud, Sigmund. 1989. "La interpretación de los sueños (1900)". Obras completas. Tomo $I V$. Buenos Aires: Amorrortu.

Ginway, M. Elizabeth y J. Andrew Brown. 2012. Latin American Science Fiction: Theory and Practice. New York: Palgrave Macmillan US.

Guijarro-Crouch, Mercedes. 2004. "Elena Aldunate". En Darrell B. Lockhart, ed. Latin American Science Fiction Writers: An A-to-Z Guide. Westport: Greenwood Press. 1316.

Hasson, Moisés. 2003. "Introducción a la literatura de ciencia ficción en Chile". Alfa Eridiani 7.II: $36-47$.

Haywood, Rachel. 2011. The emergence of Latin American science fiction. Middletown: Wesleyan University Press.

Heiremans, Carolina, Verónica Barros y Jesús Diamantino. 2016. Cuentos chilenos de terror, misterio y fantasía. Santiago de Chile: Cuarto Propio.

Hinshelwood, Robert. 2004. Diccionario del pensamiento Kleiniano. Buenos Aires: Amorrortu Editores.

Illouz, Eva. 2007. Intimidades congeladas. Buenos Aires: Katz. 
Katz, Harvey, Patricia Warrick y Martin Greenberg. 1981. Introductory psychology through science fiction. Boston: Houghton Mifflin.

Klein, Melanie. 1998. "Notas sobre algunos mecanismos esquizoides (1946)". Envidia y gratitud y otros trabajos. Obras Completas 3. Buenos Aires: Paidós. 10-33.

Lacan, Jacques. 1966. "Le séminaire sur «La lettre volé»". Écrits 1. Paris: Seuil. 11-61.

Loach, Bárbara. 1999. "María Elena Aldunate (1925)”. En Rubio, Patricia, ed., Escritoras chilenas. Tercer volumen. Novela y cuento. Santiago: Cuarto Propio. 331-342.

Lovecraft, Howard Phillips. 2010. El Horror sobrenatural en la literatura: Y otros escritos teóricos y autobiográficos. Madrid: Valdemar.

Mauron, Charles. 1963. Des métaphores obsédantes au mythe personnel: Introduction à la psychocritique. Paris: J. Corti.

Molina-Gavilán, Yolanda et al. 2007. "A Chronology of Latin-American Science Fiction, 1775-2005”. Science-fiction Studies 34: 369-432.

Montero, Antonio. 1962. Los superhomos. Santiago de Chile: Arancibia. . 1964. Hombres en clave. Santiago de Chile: Arancibia Hnos. . 1968. Acá del tiempo. Santiago de Chile: Zig-Zag. .1971. No morir. Santiago de Chile: Editorial Huda. . 1981. El círculo dramático. Santiago de Chile: Editorial Universitaria. . 2012. El Cáliz, Thule y los dioses. Valparaíso: Puerto de Escape.

Novoa, Marcelo. 2006. Años luz: Mapa estelar de la ciencia ficción en Chile. Valparaíso: Puerto de Escape.

Nueva Dimensión (ciencia ficción y fantasía). 1972. "Número dedicado a Hugo Correa". Número 33. Barcelona: Dronte.

Pizarro Obaid, Francisco. 2011. “Transformaciones y nuevas figuras de lo 'nervioso' en la construcción de los relatos de Edgar Allan Poe”. Acta Literaria 43: 79-93. . 2012. "El hombre de la multitud y el pintor de la vida moderna: la influencia de Edgar Allan Poe en la construcción del concepto de modernidad de Baudelaire". Revista Chilena de Literatura 81: 91-106. . 2016. "The Dead-Living-Mother: Marie Bonaparte's Interpretation of Edgar Allan Poe's Short Stories". The American Journal of Psychoanalysis 76.2: 183-203. . 2018. "Ciencia ficción chilena y saberes psi: el problema del doble en la obra los títeres de Hugo Correa”. Concepción, Atenea 518: 25-40.

Rank, Otto. 1973. Don Juan et le double. Paris: Payot.

Remi-Maure et al. 1984. "Science Fiction in Chile. La Science-Fiction au Chili". Science Fiction Studies 11.2: 181-189.

Rojas-Murphy, Andrés. 1988. Antología de cuentos chilenos de ciencia ficción y fantasía. Santiago de Chile: Andres Bello.

Ruperthuz, Mariano. 2016. Freud y los chilenos. Santiago: Pólvora.

Ruperthuz, Mariano y Silvana Veto. 2016. "El Psicoanalista como personaje en las novelas de Juan Marín y Samuel Gajardo. Chile 1930-1940”. Revista de Humanidades 34: $11-35$. 
Salazar, Gabriel y Julio Pinto. 1999. Historia Contemporánea de Chile I. Estado, legitimidad, ciudadanía. Santiago de Chile: Lom.

Sarlo, Beatriz. 2004. La imaginación técnica: sueños modernos de la cultura argentina. Buenos Aires: Nueva Visión.

Schultz, William. 2005. Handbook of Psychobiography. London: Oxford University Press.

Starobinski, Jean. 2008. La relación crítica. Buenos Aires: Nueva Visión.

Subercaseaux, Bernardo. 1993. Historia del libro en Chile. Santiago de Chile: Andrés Bello.

Subercaseaux, Bernardo. 2011. Historia de las ideas y de la cultura en Chile, TV politica y cultura. Santiago de Chile: Universitaria.

Vega, Omar. 2005. "En la luna: un bosquejo de la ciencia-ficción chilena". Memoria chilena. http://www.memoriachilena.cl/602/w3-article-9713.html.

Wiener, Nobert. 1988. Cibernética y sociedad. Buenos Aires: Editorial Sudamericana. 
